\title{
Thinking of Business Processes Systematically
}

\section{$1.1 \quad$ To Go}

Why should I read this book and work in a subject-oriented way? What is special about it? Is it not just another book, new wine in old bottles, enriched with more or less helpful examples and pretty pictures? What is special about subjects?
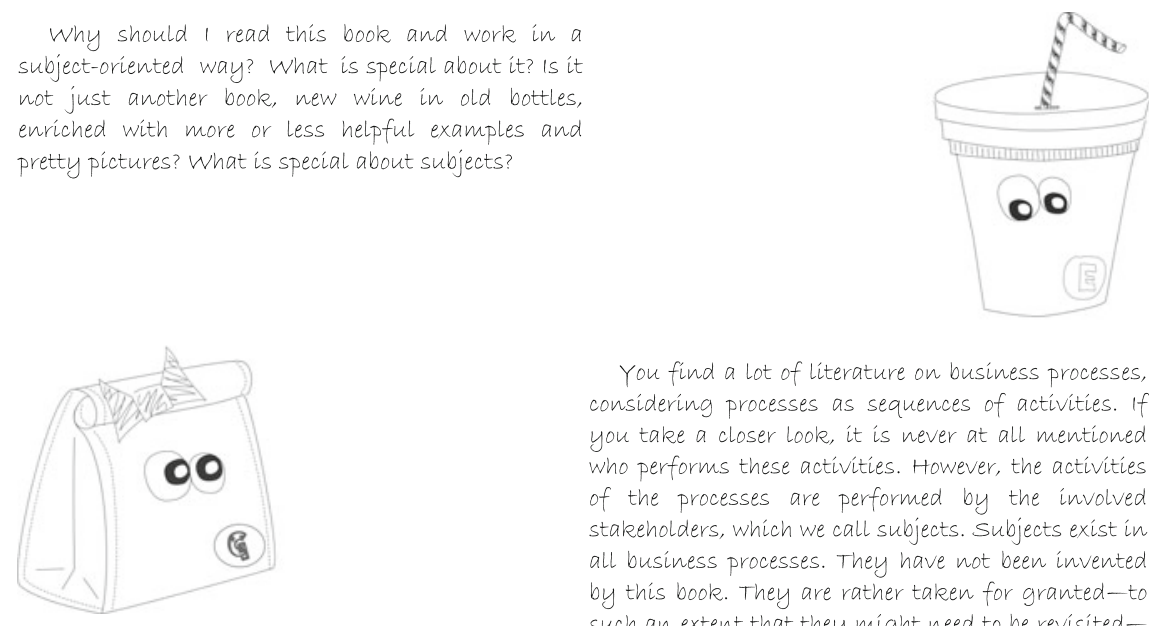

You find a lot of literature on business processes, considering processes as sequences of activities. If you take a closer look, it is never at all mentioned who performs these activities. However, the activities of the processes are performed by the involved stakeholders, which we call subjects. Subjects exist in all business processes. They have not been invented by this book. They are rather taken for granted-to such an extent that they might need to be revisitedin particular when they are considered implicit or secondary process information. Once we move the subject to the center of a process, the entire perspective on the process changes. And many open issues that could not be previously clarified can be resolved immediately. Amazingly, subject-oriented process models can be directly transformed into technologysupported workflows. See for yourself! 


\subsection{Introduction}

Today, the success of organizations is not only based on their products and services but rather on their capability to (re)design their business processes in a flexible and dynamic way (Scheer et al. 2007). In this respect we need to take different influencing factors into account:

- Globalization. Through the worldwide opening of goods, labor, and information markets, the dynamics of business activities has steadily increased. Markets are not only reinvented, which generates additional growth, but they also lead to a continuous redesign of jobs, dynamically changing portfolios and reorganized business operations. Any small change can have a far-reaching impact in a networked organization. The division of labor exceeds corporate and national boundaries.

- Stakeholder Orientation. In addition to procurement and sales, other actors and interests on the market affect the company directly or indirectly. For listed companies, the shareholders have a strong influence. The management is committed to them and tries to satisfy their striving for increasing profit. In addition, organizations need to comply with more and more regional, national, European, and other international laws and regulations, such as requirements for implementing risk management systems. In this context, mandatory equity agreements, e.g., Basel II, govern the granting of loans to organizations with a rating system.

- Progressive Penetration of the business community with information and communication technologies: in particular, internet technologies are driving forces for organizational and technical changes in almost all economic and business-relevant sectors of society. The transmission and communication platforms enable partial (if not complete) support, processing, and maintenance of exchange processes by means of electronic communication networks. Exchanging goods and services comprises the transfer of tangible and intangible elements, accompanied with configurable structure description languages such as Extensible Markup Language (XML). The latter allow the exchange of technical information across system boundaries, adapted to the respective interaction partner.

Each of these factors is directly or indirectly related to the organization and implementation of business processes or work processes. At the same time, these factors are interdependent and cannot be considered in isolation from each other. The mastery of complex business processes is one of the major challenges of every business. However, it requires concepts to deal with these challenges in a structured way (Heracleous 2003).

Accordingly, the continuous design of business processes and thereby, business process management (BPM) is of crucial importance for the success of organizations. It comprises the implementation of strategies and business models in organizational processes. As such, it goes beyond traditional management activities, resulting in cyclic planning, organization, management, and control of organizations. This has for example been vividly described by Liappas: 
"Companies often have inhomogeneous business operations. Different types of business require different types of organization. The organization needs to be geared to the market and customer requirements" (Liappas in Scheer et al. 2007, p. 44). The management of an organization is interested in two views: financial figures are generally used for looking to the past; BPM provides a means for looking to the future (Gilbert 2010).

Apparently, BPM has primarily to do with the business of a company. It is no coincidence that the word "Business" precedes Process Management. Processes are considered as leverage to operate a business according to its strategy or to align an organization according to its (public) mandate (cf. Liappas in Scheer et al. 2007, p. 44).

Subject-oriented process orientation means moving from profit orientation per se to sustainable income. The latter can be only achieved through high stakeholder satisfaction.

Two examples from consulting practices (Scheer et al. 2007):

- A market-leading chemical company has identified cost leadership as the most important success factor in its business. Product and process costs are the two key leverages for this purpose. The production network, which has been responsible for product manufacturing, guaranteed low product cost. The company decided to focus its efforts on developing an effective, efficient process landscape. It should, on the one hand both simplify and automate the customer interaction with the company and, on the other hand, ensure that the organization acts in compliance with the business model it has adopted.

- A European authority has decided to use business processes as a means of implementing its strategy and optimizing its resources. As a basis for subsequent activities, a business process model was created that reflected the statutory mandate to that authority. Based on this model, several design projects have been set up successfully, such as zero-based budgeting, optimization in various areas of the organization, and the introduction of a new ERP (enterprise resource planning) system.

Public service organizations often ask whether they can use the same methods as companies with market orientation. The only difference between the two of them is the purpose of the organization: one wants to earn money, and the other has to administer the law. However, the approach to the fulfillment of each objective can be the same in both cases.

These cases show tangible connections between business processes and their impact on organizations. Nevertheless, handling business processes at a high level of abstraction is the greatest risk for BPM today: the trivialization of dealing with processes. It is challenging to deal simultaneously with the company's business model, the processes, the planning and control systems, rules of conduct, information technology, and personnel matters. 
Lack of knowledge about business processes can lead to wrong decisions with negative consequences for the organization.

Managers have to deal with the planning, monitoring, and controlling of business processes. Such a traditional focus on business-relevant processes is often chosen in practice; however, this results in unsatisfying outcome and low acceptance of BPM. Even when organizations publish their process descriptions on the intranet, these pages are rarely visited. Why? Since the process documentation is already memorized, or nobody is actually interested in it? "Processes cannot be decoupled from the business!" (Liappas in Scheer et al. 2007). They rather control what happens in the organization.

Another problem is the generally known fact that process issues are pursued by various stakeholders. Processes of an organization are actively incorporated and modeled by business departments, as well as by IT departments. However, IT departments take a different, more technical perspective on the processes. When stakeholders involved in the processes are interviewed, they do not speak the same language as process modelers or organization developers. A major government agency has reported that the process of attaining a thorough understanding causes most of the effort in process management. This is already mirrored in the terms business process and workflow. The business processes of individual departments are mainly implemented using information technologies. A business process is technically refined and becomes a workflow. The latter is often described using different methods than those used for describing business processes, leading to incoherent and inconsistent specifications. Hence, such a transformation can lead to a significant loss of information, due to the mapping and translations. In addition, process descriptions are usually not detailed sufficiently by concerned members of the organization to be transferred without further effort into a workflow system. This causes additional effort for a successful implementation, including making assumptions about the actual work procedures.

The design of business processes should be in line with the business intelligence of an organization (Kemper et al. 2004). It bundles relevant information about organizations. By modeling business processes, organizations can build up business intelligence, i.e., they can collect their knowledge to achieve organizational goals and transparent models for the targeted processing. Information and communication technologies play a major role in the presentation, imaging, and processing of information.

Moreover, the organization has to be recognized as a system consisting of people and their communication relationships. The individual stakeholders are responsible for implementing the business processes. Their qualifications and motivation are crucial for the success of the business. System thinking helps to recognize the mutual relationships of all relevant elements and their relationships within an organization (which is then considered a system). 
The more organizational changes are triggered through models, the more important the explicit consideration of contextual information becomes, so-called system thinking.

The generation of added value, therefore, requires an integrated BPM approach that takes into account many different aspects in a balanced way. To this end, a number of different capabilities are required, in particular product orientation, customer (or market) orientation, system thinking, and abstract thinking in terms of models:

- Product orientation. A market-driven orientation toward partners and products (Lehner et al. 2007) includes services and software and represents one of the key factors of process design. The use of corporate resources (information, materials, skills, etc.) should be aligned with the life cycle of products.

- Customer orientation. In addition to product orientation, customer orientation is the major trigger for the design and change management of an organization. The life cycle of a product has to be aligned with customer expectations (cf. debate about climate change) and is subject to changes according to customer behavior. Nevertheless, development, production, and distribution of products or services have to comply with the principles of economic efficiency.

- System thinking requires explicit recognition of context of all processes of an organization and linking of information across system boundaries, especially for decision-making purposes.

- Abstract thinking in terms of models, as a principle to approach capabilities and problems, allows focusing on relevant events and structures of the world as observed by humans. It strives for the "essence" without losing target-specific context.

The primary area of design for change management in integrated BPM is represented by organizations being seen as increasingly self-regulated sociotechnical systems (Exner et al. 2010). IT systems, especially systems supporting the operational flow, such as workflow management systems, are embedded in the context of a work organization and need to be adapted according to economic benefits and human work requirements. Models, methods, and tools need to be applied accordingly.

Systemic BPM is context sensitive in two respects: on the one hand, organizational, technical, and human-social factors are considered, including their mutual relationships; on the other, these factors, along with their mutual dependencies, form the context for all BPM activities (ranging from the acquisition of work knowledge to evaluation and execution).

A comprehensive method for the concrete implementation of an integrated BPM-oriented approach is subject-oriented business process management (S-BPM). It brings the subject of a process to the center of attention. In doing so, it considers business processes and their organizational environment from a new perspective, meeting organizational requirements in a much better way. 
At the S-BPM-ONE Conference in 2009, Hagen Buchwald differentiated between three different phases of perspectives in computer science, starting with flowcharts (predicate orientation) in 1970 (Buchwald 2010, p. 20f). This changed around 1990 by the paradigm shift to object orientation. And, again 20 years later, in 2010, a further change occurred, the shift to subject orientation.

Integration is more than the sum of its parts. The subject-oriented management process is not only results-oriented but rather substantially reshapes modeling as a comprehensive construction process; in the long run, managers trust their staff to reflect business processes interactively and to (re)construct them dynamically.

S-BPM provides a coherent procedural framework of reference to manage business processes of an organization: its focus is on the cooperation of those involved in the strategic, tactical, and operational issues, sharing their knowledge in a networked structure of the organization. Thus, S-BPM is an integrated approach to organizational design and development of an organization. Regardless of the complexity of a case at hand, it can be handled on a technological basis, as all validated behavior models can be directly executed. Moreover, the concept and precise prescription of technological behavior allow the seamless integration of SBPM models into existing, and heterogeneous IT landscapes.

The only requirement for acquiring S-BPM competence is a good command of natural language. Hence, based on the findings of developmental psychology and linguistics, we first explain in Chap. 2 that for complete S-BPM specifications sentence natural language semantics has to be used. In this way, business process owners are able to ensure that business requirements of internal and external stakeholders are entirely met. All involved people, regardless of their functional roles, are able to learn how to model in a subject-oriented way, because this approach is closely tied to operational actions and provides a direct reference to existing information exchange processes between stakeholders. Hence, in this chapter, we also explain how information systems can be developed using $\mathrm{S}$ $\mathrm{BPM}$, in order to meet different requirements on the implementation level in a straightforward way.

In the Chap. 3.5 we detail the procedures behind S-BPM when developing organizations on the basis of subject-oriented business process models. The process model is coherent and justifies its practicality. Its development has been based on widespread experiences with the use of S-BPM. Chapters 4-11 detail the various bundles of activities of the S-BPM method. Starting out with analysis, we demonstrate how subject orientation can develop and be experienced by gradually focusing on communication for service provision. The subject-oriented perspective is also of benefit for real-time execution of specifications as well as for solving complex problems due to the simple, networked modeling structure of S-BPM. In Chap. 12, we provide a formal specification of the modeling method. In Chap. 13, 
we illustrate how each of the previously described activity bundles can be supported through the use of appropriate software tools.

In the final part of the book, we show in Chap. 15 a typical round-trip from current S-BPM practice. We also mutually contrast existing formal methods for modeling business processes in the Chap. 14. The approaches are described on the basis of their fundamental concepts. We also explain what relationship natural languages have with formal languages of computer science in general, and how the subject-oriented modeling method could be developed out of the structure of natural language. These considerations complete our round-trip that started with discussing natural language capabilities required for subject-oriented modeling in the course of human-centered design of socio-technical systems.

Each chapter begins with a summary of key findings with respect to the addressed topic, called "To Go": in a fictional dialog of actors relevant for S-BPM the content of each chapter is addressed in an engaging and entertaining form.

The glossary and index at the end of the book should facilitate profound discussions and serve as a quick reference to S-BPM concepts and operational methods.

\section{References}

Buchwald H (2010) The Power of 'As-Is' Processes, Springer CCIS 85, pp. 13-23, 2010.

Exner, A., Exner, H., Hochreiter, G., Unternehmens(Selbst)Steuerung - Ein praktikables Managementmodell, in: Organisationsentwicklung - Zeitschrift für Unternehmensentwicklung und Change Management, No. 2, S. 56-65, 2010.

Gilbert, P., The next decade of BPM, in: Hull, R., Mendling, J., Tai, S. (Eds.), Business Process Management, Springer LNCS 6336, Berlin 2010.

Heracleous L., Strategy and Organization - Realizing Strategic Management, Cambridge/UK 2003.

Kemper, H.-G., Mehanna, W., Unger, C., Business Intelligence - Grundlagen und praktische Anwendungen, Wiesbaden 2004.

Lehner, F., Wildner, S., Scholz M., Wirtschaftsinformatik - Eine Einführung, München 2007.

Scheer, A.-W., Kruppke, H., Jost, W., Kindermann, H. (Hrsg.), Agilität durch ARIS-Geschäftsprozessmanagement, Jahrbuch Business Process Excellence 2006/2007, Berlin 2007.

Open Access. This chapter is distributed under the terms of the Creative Commons Attribution Non-commercial License, which permits any noncommercial use, distribution, and reproduction in any medium, provided the original author(s) and source are credited. 